\title{
Does health insurance coverage lead to better child health? Evidence from China
}

\author{
Lu Chen ${ }^{1,2} \cdot$ Lanlan $\mathrm{Chu}^{3}$
}

Received: 6 May 2019 / Accepted: 19 July 2019 / Published online: 30 July 2019

(c) China Population and Development Research 2019

\begin{abstract}
Using data from the China Health and Nutrition Survey, this study investigated the impact of health insurance coverage on children's health in China. To address the potential endogeneity between insurance and health, we adopted the instrumental variable probit model. We found that insurance enrollment significantly improved the health of children, especially urban children, but there was no significant insurance effect across gender. After using the propensity score matching method, an alternative measure of child health, and a sub-sample of children aged above 10, our major finding of the insurance effect on child health is verified and robust. We further conducted the path analysis by identifying three potential paths through which medical insurance improved child health. We found that child health behaviour and nutritional intake are the effective paths between insurance enrollment and health status. These results provided implications for policy makers in constructing and developing the supportive system of child medical insurance in China.
\end{abstract}

Keywords Medical insurance $\cdot$ Child health $\cdot$ IV probit $\cdot$ Path analysis $\cdot$ China

JEL classification $\mathrm{I} 12 \cdot \mathrm{I} 13 \cdot \mathrm{I} 14$

Lanlan Chu

chu@bvu.edu

Lu Chen

chenlu@nankai.edu.cn

1 School of Finance, Nankai University, No. 38 Tongyan Road, Jinnan District, Tianjin 300350, People's Republic of China

2 Research Center of Healthy Aging and Social Security, Nankai University, No. 38 Tongyan Road, Jinnan District, Tianjin 300350, People's Republic of China

3 Harold Walter Siebens School of Business, Buena Vista University, 610 W. 4th Street, Storm Lake, IA 50588, United States 


\section{Introduction}

Health is a comprehensive status of physical, mental, and social well-being. According to Constitution of the World Health Organization (1946), the enjoyment of the highest attainable health standard is one of the essential rights of every human being. Health is a form of human capital, as durable and accumulating as physical capital (Lucas 1988). While health depreciates over time, it can be increased with health investment, such as medical care, leisure, and exercise. Medical insurance is considered a primary mechanism that reduces medical expenditures incurred by disease risks. Its direct function is to lower economic barriers for medical treatments, to manage financial risk and ensure financial accessibility of health care services. Since the utilization of medical services is specifically designed for health (Grossman 1972), the ultimate goal of health insurance is to maintain and promote the individual's health outcome.

In China, the universal coverage of basic medical insurance is a fundamental health policy of the Chinese government to promote the reform of the medical system. In 1998, China officially established basic medical insurance for urban employees, covering all employers in urban China. In 2003, the new rural cooperative medical scheme (NRCMS) was piloted in selected rural areas, and then gradually expanded to the entire rural population. In 2007, the urban resident basic medical insurance (URBMI) was established in urban areas. On this basis, in 2016, the State Council issued the "Opinions on Integrating the Basic Medical Insurance System for Urban and Rural Residents" to unify the two systems of the NRCMS and URBMI into basic medical insurance for all residents of the country. Nevertheless, the universal health insurance coverage is an enormous expense for the Chinese government. Based on the Healthy China report released by World Bank in 2019, from 2009 to 2014, the Chinese government has invested over 3 trillion RMB into the health system to expand the coverage of the social insurance system and to increase the accessibility of public health services. In this context, it has become a major interest of health economists to examine whether such huge expenditures can improve individuals' health status in China. Only by accurately assessing its health impact, can medical insurance be compared with other interventions through costeffectiveness and cost-efficiency analysis. As a result, relevant public policies can be adjusted and optimized to produce the greatest social benefits given limited economic and social resources.

In this study, we attempted to explore the health performance of basic medical insurance and the paths through which medical insurance affects health. Since health investment in children is more effective than adults, this study used the subpopulation of children to investigate this topic. First, the rate of health depreciation in childhood is relatively low before growing into an adult. Second, the health status of children has a significant impact on their health in later life, which will eventually affect their educational and labour outcomes (Currie et al. 2008; Roseboom et al. 2006; Naudeau et al. 2011; Ampaabeng and Tan 2013). Overall, children's health investment not only plays a central role in determining their personal well-being but also the health of the whole society and contributes towards the country's future. 
The aim of this paper is to explore the effect of the public health insurance coverage on child health using data from the China Health and Nutrition Survey (CHNS). The rest of this article is structured as follows. The literature review is presented in the next section. Section 3 describes the data and Sect. 4 presents the econometric model. The empirical results are interpreted in Sect. 5. Section 6 presents the path analysis and results. Section 7 is the discussion and Sect. 8 concludes.

\section{Literature review}

Hundreds of studies have researched the overall relationship between health insurance and health. The results of these studies, however, have been mixed (Howell and Kenney 2012). Levy and Meltzer $(2001,2008)$ demonstrated that in general, health insurance can improve health. Sommers et al. (2012) found that Medicaid expansions significantly reduced mortality among adults, particularly those aged between 35 and 65 years, minorities and low-income adults. Furthermore, Sommers et al. (2017) reviewed various studies and summarized that expanding health insurance coverage increased access to health care and produced significant benefits to health. Nevertheless, a few studies failed to show a relationship between health insurance coverage and health (Perry and Rosen 2001). Through the RAND Health Insurance Experiment (HIE), Newhouse and the Insurance Experiment Group (1993) indicated that insurance generosity was not significantly associated with the health of an average adult. Miller and Wherry (2017) used data from the National Health Interview Survey and indicated that Medicaid expansions under the Affordable Care Act (ACA) were not associated with significant change in the likelihood of respondents' health status. Similarly, Courtemanche et al. (2017) used data from the Behavioural Risk Factor Surveillance System and found the ACA did not have statistically significant effects on self-assessed health for the full sample.

As the research progresses, several studies have started using subpopulation groups, such as infants and children, to explore how health insurance affected their health. These studies are mostly concentrated in the U.S. and the conclusions are inconsistent. Among studies specifically examining the impact of health insurance on children's health, most of them demonstrated a positive association between health insurance and child health (Currie 1995; Leininger and Levy 2015). For instance, Currie and Gruber (1996a) showed that the expansion of Medicaid eligibility significantly reduced child mortality by $12.77 \%$. Currie and Gruber (1996b) used a simulation model and found that a $30 \%$ increase in health insurance eligibility significantly reduced infant mortality by $8.5 \%$. Howell et al. (2010) found that a $10 \%$ increase in Medicaid eligibility resulted in a roughly $3 \%$ decline in child mortality. Moreover, Joyce and Racine (2005) exhibited that the introduction of the State Children's Health Insurance Program improved the health outcome of children. On the other hand, a few studies indicated there were no significant relationship between insurance eligibility and child health. For example, De La Mata (2012) found that Medicaid eligibility had no significant effects on the health outcomes of U.S. children in the short and medium run. 
Internationally, there exists very few studies on Chinese children. Liu et al. (2013) used the 1989-2006 CHNS data to explore the impact of insurance on child health and nutritional status across urban and rural areas in China. They conducted multivariate regression analysis and found that health insurance coverage, demographic characteristics, parents' socioeconomic status, and health behaviours played an important role determining the disparities in child health between rural and urban China. Using the 2006-2009 waves of CHNS and fixed effect method, Liu and Zhao (2014) estimated the effects of the URBMI on health care utilization in urban China. They found that the URBMI significantly improved the health care utilization among urban children. However, these two studies did not present a direct relationship between health insurance and Chinese children's health. Using data from the 2006 China Agricultural Census, Chen and Jin (2012) examined the impact of the NRCMS on various outcomes of children living in rural China. They employed a difference-in-different propensity score method and found that the NRCMI did not have a significant effect on child mortality. Though they presented several findings regarding the effect of health insurance on the mortality of rural children, there were no illustrations on the association between medical insurance and other health outcomes of Chinese children.

This paper uses the CHNS data to empirically study the impact of health insurance on child health in China. It attempts to contribute to the existing literature in three distinct aspects. First, it widens the research on the health of children in developing countries from the perspective of health insurance enrollment using a micro survey data in China. Second, we used the instrumental variable (IV) method to control for the possible endogeneity issue of health insurance in estimations. Third, we identified and thoroughly analysed the paths through which child health is promoted with the access of health insurance.

\section{Data}

\subsection{Data description}

The CHNS, initiated in 1989, includes representative Chinese participants from various economic status, health indicators, and geography. The goal of the survey is to explore the impacts of social and economic changes on Chinese people's health and nutritional status. The survey was fully started in 1991, consisting of eight provinces: Guangxi, Guizhou, Henan, Hubei, Hunan, Jiangsu, Liaoning and Shandong; a ninth province, Heilongjiang, was included in 1997. In 2011, Beijing, Shanghai and Chongqing, were further added to the survey. By then, the CHNS consisted of 27,447 individuals from 5884 households. Based on the 2012 China Health Statistical Yearbook, the twelve sample units included in the CHNS represented approximately $47 \%$ of China's population. Throughout the paper, children are defined as those less than 18 years old. We added one child from each household in this analysis. For households with two or more children, the oldest child was included. The CHNS is an unbalanced panel data. We used the pooled data in the survey waves of 2004, 2006, 2009 and 2011 for this study. 


\subsection{Dependent variables}

We used the variable of 'height-for-age Z-score (HAZ)' to measure child health status. HAZ is a measurement of childhood malnutrition and has been extensively used as a good children's health indicator (WHO, 2006). It has been adopted as a child health measure in existing literature, such as Wagstaff et al. (2003), Chen et al. (2007), Osberg et al. (2009), Chen et al. (2014) and Goode et al. (2014). HAZ is calculated in Eq. 1 and represents the standard deviation of how many times the individual's height differs from the median height of their age group.

$$
H A Z_{i j}=\frac{\text { height }_{i j}-\overline{\text { height }}_{j}}{\text { Std.Dev }}
$$

Here, $H A Z_{i j}$ refers to the HAZ index for a child $i$ in the group $j$ defined by children's gender and age; height $_{i j}$ indicates the height of the child $i$ in group $j$; $\overline{\text { height }}_{j}$ indicates the median height for the reference children's group with the same gender and age, and $S t d$. Dev $v_{j}$ represents the standard deviations of height for the reference group $j$. The median heights, height $t_{i j}$, and the standard deviations, Std. Dev $v_{j}$, for the reference group were published by the WHO and used as reference standards.

Though the HAZ is a continuous variable, we favour a binary variable of HAZ index for three reasons. First, our aim is to explore whether the health insurance enrollment reduces the possibility of children being stunted. In this sense, a binary variable is effective to indicate whether or not the child in the survey was stunted. A continuous HAZ generally means that the taller a child is, the better the health is. However, this statement may not be always true. Second, the stunting level of child health has been used as a mark of moderate malnutrition in prior studies such as Liu et al. (2013) and Peng and Conley (2016). Third, the WHO recommends using the cut-off for HAZ of below -2 standard deviations to identify children suffering from moderate to severe malnutrition. Following this standard, a child whose $H A Z_{i j}$ is less than -2 is classified as being stunted, and greater than -2 is considered in good health. HAZscore $i j$ is a dichotomous variable, as presented in Eq. 2. We set 1 for a child $i$ whose HAZ is above -2 , and 0 for those HAZ below or equal to -2 .

$$
H A Z_{\text {score }_{i j}}= \begin{cases}1, & \text { if } H A Z_{i j}>-2 \\ 0, & \text { if } H A Z_{i j} \leq-2\end{cases}
$$

\subsection{Explanatory variables}

Table 1 presents the list of variables and definitions for this study. The explanatory variables are divided into three categories: key explanatory variables, control variables and channel variables. There are three explanatory variables. First, the variable of insurance indicates whether a child is covered by any public medical insurance. This variable derives from the survey question (M1) of whether the respondent has any medical insurance, which is a combination of six types of insurance. If the respondent has either the NRCMS or URBMI, the variable of insurance takes a value of one, and zero if the respondent does not have any medical insurance. 


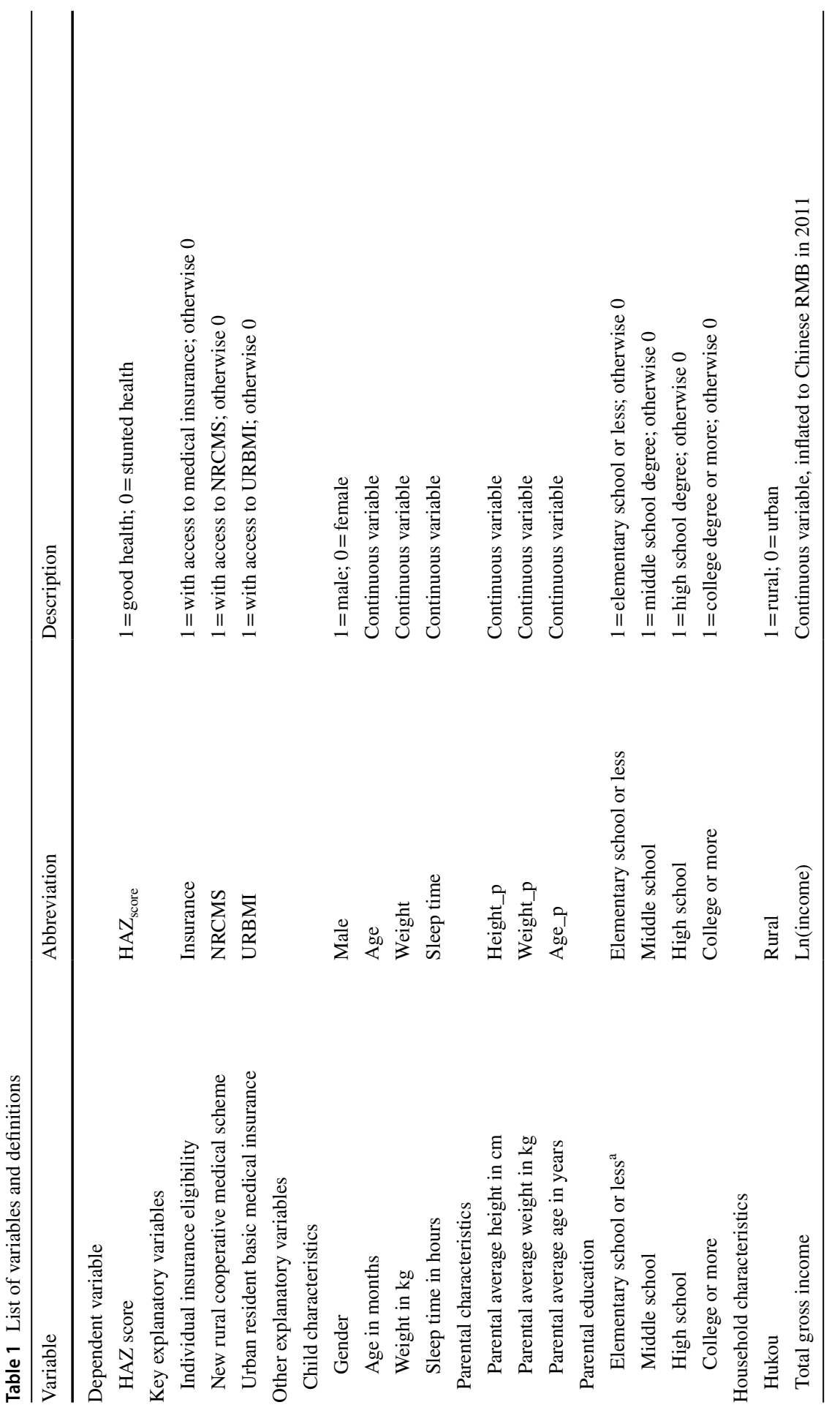




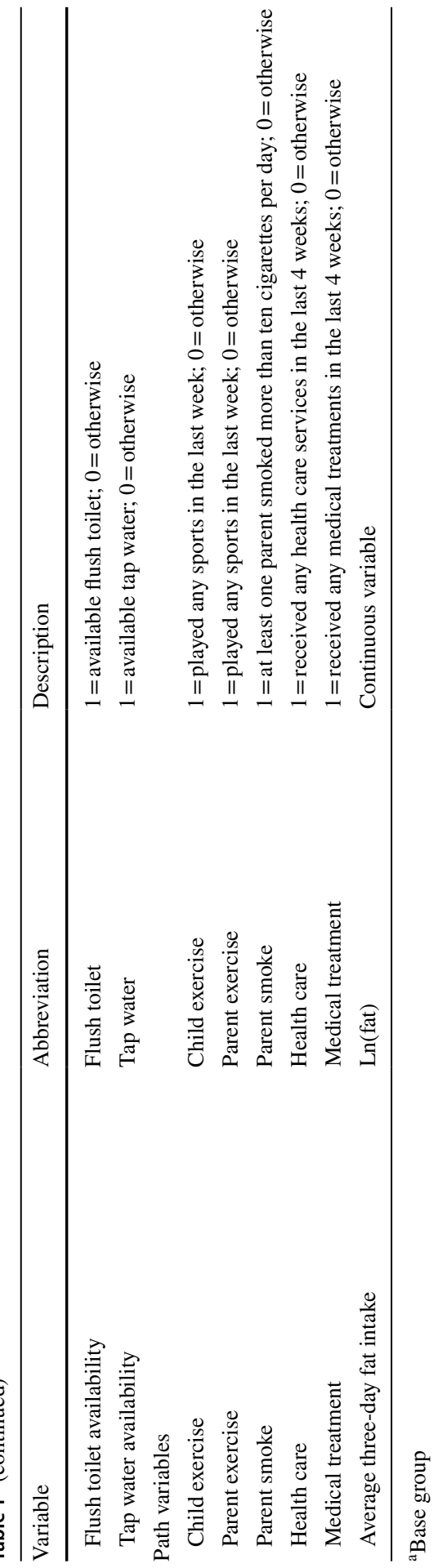


Second, the variable of NRCMS takes a value of one if a child is covered by the new rural cooperative medical scheme in rural China and zero if the child is not covered by any medical insurance. Similarly, the variable of URBMI takes a value of one if the child participates in the urban resident basic medical insurance in urban areas and zero if the child is not enrolled in any medical insurance.

Existing literature has indicated that observable aspects of demographic and socioeconomic factors are associated with health outcomes (Pincus et al. 1998; Ross and Mirowsky 2000). Thus, we controlled for these factors regarding children, their parents and families. Child characteristics consist of children's age, gender, weight and sleep time; parental characteristics contain parental educational achievement, height, weight and age; family variables include household registration (hukou), income, tap water and flush toilet availabilities. Parental education level is determined by the highest education level achieved by mother or father and grouped into four categories: elementary school or less, middle school, high school and college or more, of which elementary school or less is the reference group. Given the potential effects of both mother and father, parental height, weight and age are determined by the average values of parents. We used the gross household income inflated to 2011 for the variable of household income. The year dummies were included to control for the time effects.

\subsection{Descriptive statistics}

Descriptive statistics of all the variables for the full, insured and uninsured samples are presented in Table 2. After dropping the respondents with missing information on key explanatory variables, the final analysis sample is a pooled cross-sectional data set with 5786 respondents, of which the number of rural and urban children is 3748 and 2038, respectively. As indicated, there are 2649 children that enrolled in public medical insurance and the participation rate was approximately $45.8 \%$. Based on the information on HAZ score, 533 children were malnourished, accounting for $9.2 \%$ of the whole sample. The HAZ score of the insured group is significantly higher than that of the non-insured group at a level of $1 \%$. Table 2 also indicates that the differences between insured and non-insured children are significant on sleep time, hukou, household income, parental height, weight, age and education attainment.

\section{Method}

Most of the previous studies have adopted three different approaches-randomized experiments, multivariate regression analysis and IV method-to determine the effect of health insurance on an individual's health outcome (Allen et al. 2010; Levy and Meltzer 2001, 2008). The first group of studies used interviews and randomized experiments, such as the RAND Health Insurance Experiment, to explore the insurance effect on health (Brook et al. 1983; Newhouse and the Insurance Experiment Group 1993). More recently, Allen et al. (2010) used 
Table 2 Descriptive statistics

\begin{tabular}{|c|c|c|c|c|c|c|c|}
\hline & \multicolumn{2}{|l|}{ Total } & \multicolumn{2}{|c|}{ Insured } & \multicolumn{2}{|c|}{ Non-insured } & \multirow[t]{2}{*}{$T$ test } \\
\hline & Mean & SD & Mean & SD & Mean & SD & \\
\hline \multicolumn{8}{|l|}{ Dependent variable } \\
\hline $\mathrm{HAZ}_{\text {score }}$ & 0.908 & 0.289 & 0.929 & 0.256 & 0.890 & 0.312 & $* * *$ \\
\hline \multicolumn{8}{|l|}{ Explanatory variables } \\
\hline Insurance & 0.458 & 0.498 & & & & & \\
\hline NRCMS & 0.509 & 0.500 & & & & & \\
\hline URBMI & 0.365 & 0.481 & & & & & \\
\hline Male & 0.523 & 0.499 & 0.524 & 0.499 & 0.523 & 0.499 & \\
\hline Age & 108.9 & 60.14 & 109.0 & 56.07 & 108.8 & 63.38 & \\
\hline Weight & 32.78 & 15.74 & 33.05 & 15.56 & 32.54 & 15.89 & \\
\hline Sleep time & 9.505 & 1.707 & 9.437 & 1.509 & 9.562 & 1.856 & $* * *$ \\
\hline Rural & 0.647 & 0.477 & 0.719 & 0.449 & 0.587 & 0.492 & $* * *$ \\
\hline Ln(income) & 10.23 & 1.051 & 10.42 & 1.020 & 10.07 & 1.052 & $* * *$ \\
\hline Height_p & 162.6 & 4.238 & 162.8 & 4.124 & 162.3 & 4.320 & $* * *$ \\
\hline Weight_p & 61.52 & 6.472 & 62.11 & 6.449 & 61.02 & 6.450 & $* * *$ \\
\hline Age_p & 36.62 & 5.591 & 36.83 & 5.079 & 36.44 & 5.984 & $* * *$ \\
\hline \multicolumn{8}{|l|}{ Parental education } \\
\hline Elementary school & 0.267 & 0.442 & 0.317 & 0.465 & 0.225 & 0.417 & $* * *$ \\
\hline Middle school & 0.405 & 0.490 & 0.385 & 0.486 & 0.422 & 0.493 & $* * *$ \\
\hline High school & 0.153 & 0.359 & 0.117 & 0.321 & 0.182 & 0.386 & $* * *$ \\
\hline College or more & 0.175 & 0.380 & 0.181 & 0.385 & 0.171 & 0.376 & \\
\hline Flush toilet & 0.470 & 0.499 & 0.473 & 0.499 & 0.468 & 0.499 & \\
\hline Tap water & 0.770 & 0.420 & 0.778 & 0.415 & 0.764 & 0.424 & \\
\hline \multicolumn{8}{|l|}{ Path variables } \\
\hline Child exercise & 0.658 & 0.474 & 0.699 & 0.458 & 0.623 & 0.484 & $* * *$ \\
\hline Parent exercise & 0.110 & 0.313 & 0.110 & 0.314 & 0.110 & 0.313 & \\
\hline Parent smoke & 0.440 & 0.496 & 0.395 & 0.488 & 0.478 & 0.499 & $* * *$ \\
\hline Health care & 0.062 & 0.242 & 0.062 & 0.241 & 0.063 & 0.243 & \\
\hline Medical treatment & 0.110 & 0.313 & 0.121 & 0.327 & 0.101 & 0.301 & $* *$ \\
\hline $\operatorname{Ln}($ fat $)$ & 3.807 & 0.621 & 3.822 & 0.608 & 3.794 & 0.631 & $*$ \\
\hline Observations & 5786 & & 2649 & & 3137 & & \\
\hline
\end{tabular}

$* * * \mathrm{p}<0.01, * * \mathrm{p}<0.05, * \mathrm{p}<0.1$

the Oregon Health Insurance Experiment to study the likely effects of expanding public health insurance in a low-income population. Due to the difficulty and high cost of implementing natural experiments, this approach is rarely used. The second group of studies employed multivariate regression analysis to control for observable differences between insured and uninsured individuals, such as age, income and education (Brown et al. 1998). Most studies in this group suggested that expanding health insurance coverage improved public health (Hadley 2003). However, these results are possibly biased because the variation in the insurance 
effect on health can be caused by unobservable factors. Due to these limitations, the third group adopted the IV method to address for the possible endogeneity of medical insurance on individuals' health (Currie and Gruber 1996a; Dor et al. 2006; Lei and Lin 2009).

Since households who enrolled in public health insurance might have other unobservable characteristics that could simultaneously influence their enrollment decisions and health status, thus there may exist the endogeneity of individual insurance enrollment status and health. Such a possibility of endogeneity is verified by the Hauseman' exogeneity test of 5.64 with a p value of 0.02 in this study. Therefore, we used the instrumental variable probit model (IV probit) to examine the insurance effect on child health. According to Levy and Meltzer (2008), the state-level variables are feasible instruments. Dor et al. (2006) used marginal tax rates, average unemployment rate and average rate of unionization as instruments to the eligibility of private insurance. Currie and Gruber (1996a) instrumented the individual insurance eligibility with the fraction of children in the same state, year and age who were eligible to insurance. Lei and Lin (2009) used the country NRCMS enrollment status as an IV for individual NRCMS enrolment status to study the impact of health insurance on health outcomes in China.

Based on previous research (Zhou et al. 2015, 2018), we used the provincial insurance participation rate (Insurance_province), calculated by dividing the number of children enrolling in public insurance by the total number of children in the same province and year surveyed in the CHNS, as the IV for an individual child's public health insurance enrollment status. The IV probit model is estimated in two stages and presented as follows:

$$
\begin{aligned}
& \text { Stage 1: } \text { Insurance }_{i}=\beta_{0}+\beta_{1} \text { Insurance_province }_{i}+\xi_{i} \\
& \text { Stage 2: } \text { Health }_{i}^{*}=\alpha_{0}^{*}+\alpha_{1}^{*} \widehat{\text { Insurance }}{ }_{i}+X_{i}^{\prime} \alpha_{2}^{*}+\epsilon_{i} \\
& \text { Health }_{i}= \begin{cases}1, & \text { if Health } \\
0, & \text { if Health }\end{cases}
\end{aligned}
$$

where insurance_province ${ }_{i}$ represents the IV to individual health insurance enrollment status.

$X_{i}^{\prime}$ is a vector of demographic and socioeconomic variables. Insurance ${ }_{i}$ is the predicted value of individual insurance enrollment estimated in Stage 1. Health ${ }_{i}^{*}$ denotes the latent variable representing the net benefits of health; Health is an indicator variable equal to 1 if an individual child $i$ is in good health and 0 if the child is stunted. The health status of children (health ${ }_{i}$ ) was measured by $H A Z_{\text {scoreij }}$, which is presented in Eq. 2. $\alpha_{0}^{*}$ is the coefficient of interest, a consistent estimate when substituting Insurance ${ }_{i}$ in Eq. 4. $\xi_{i}$ and $\epsilon_{i}$ are normally distributed error terms in Eqs. 3 and 4, respectively. 


\section{Results}

\subsection{Impact of health insurance on child health}

Table 3 reports the estimated results of the whole sample and two sub-samples to distinguish hukou and gender using the IV probit model. In the full sample analysis, we presented the results of the first stage and second stage, respectively. As indicated in column 1 of Table 3, the variable, Insurance_province, satisfied the requirements of relevance and exogeneity for an effective IV. First, the insurance participation rate at the provincial level reflects the acceptance of the medical insurance system in various regions. Due to information sharing, social network and other factors, the provincial participation rate highly correlates with the individual participation rate. As shown in column 1 of Table 3, the first-stage $F$ statistics is 301.1 with a $p$ value of 0.000 , which suggests that the first requirement of an effective IV is satisfied. Second, the province-level insurance participation rate is exogenous to the individual's health status. The province-level insurance participation rate is not directly related to the disturbance item in Eq. 3. Moreover, the Wald test of exogeneity presented at the bottom of Table 3 is significant at the level of $1 \%$, which confirms the endogeneity of health insurance and verifies the appropriate use of the IV probit model.

Column 2 of Table 3 presents the estimated marginal effects of medical insurance on child health in the full sample. When children are covered by any public medical insurance, the possibility of children being stunted is $11.3 \%$ lower than uninsured children. Columns 3 and 4 of Table 3 report the heterogenous effect of health insurance on child health between urban and rural areas. Though the Chinese government has made considerable progress in promoting the health of children over the last few decades, the urban and rural gap in child health remains large due to factors such as health care access, service capacity and quality. We found that enrolling in the NRCMS and the URBMI significantly improved the health of rural and urban children by $5.9 \%$ and $37.4 \%$, respectively. Moreover, columns 5 and 6 present the different effects of health insurance on the health of boys and girls. As indicated, participating in any public medical insurance reduces the possibility of boys and girls being stunted by $10.5 \%$ and $12.3 \%$, separately.

Furthermore, we used the seemingly unrelated estimation to test whether there exist significant distinctions in the estimated health insurance effect across various subsamples. We found the effect of public health insurance on urban children is significantly larger than their rural counterparts. Nevertheless, there is no significant difference of insurance effect between boys and girls.

\subsection{Robustness analysis}

We conducted the robustness checks of our findings from three different aspects. First, we used the propensity score matching (PSM) method developed by Rosenbaum and Rubin (1983) to check the findings in the previous stage. Second, we used a different sample of children aged beyond 10 years old to explore the impact of public medical 


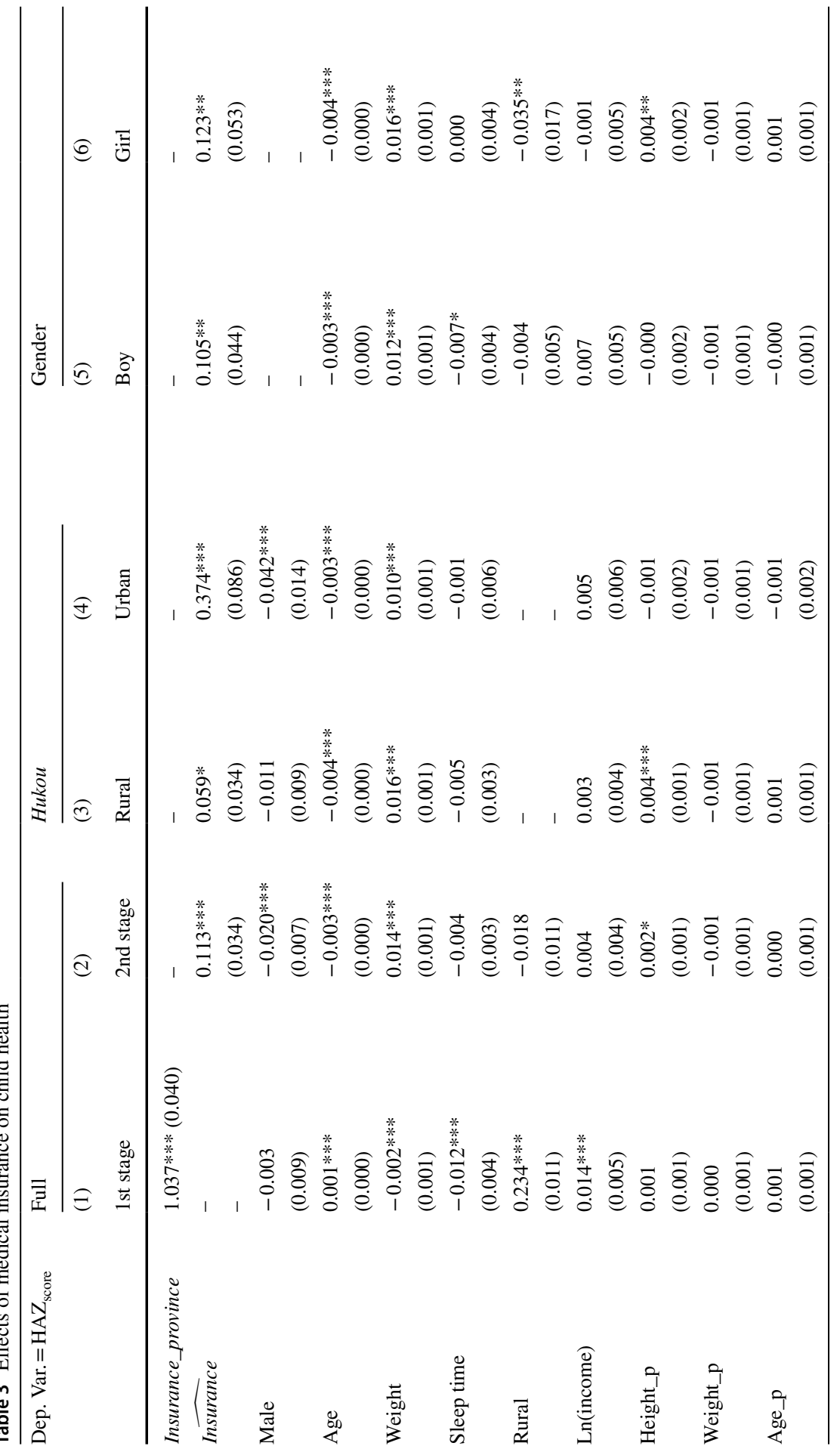




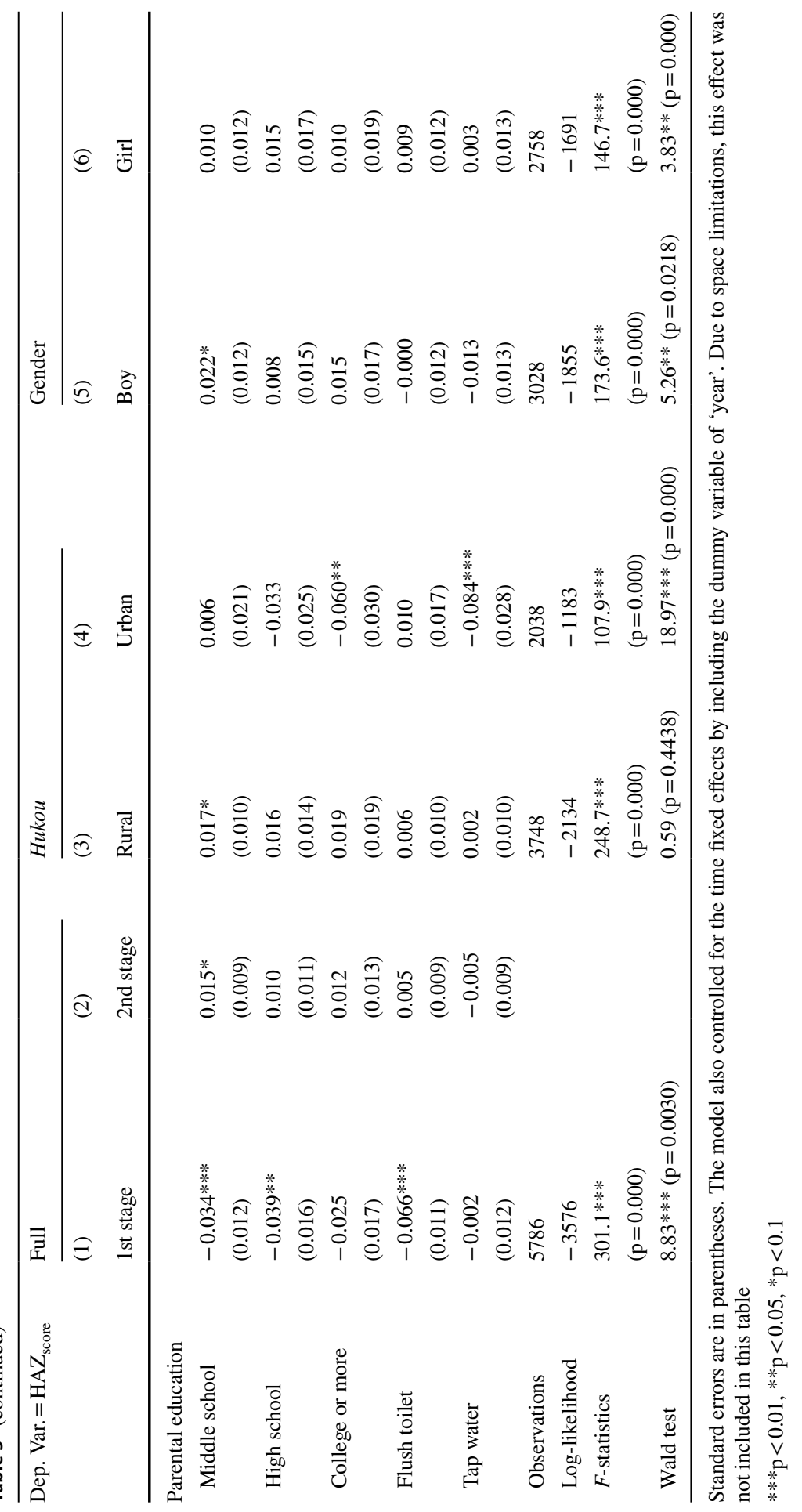


insurance on child health. Third, we adopted body mass index for-age Z-scores (BMIZ) to replace the variable, HAZ, to measure the health status of children. Each robustness check is estimated using IV probit model.

Dehejia and Wahba (2002) have identified that the PSM method can obtain accurate estimates of treatment effects in non-experimental settings. The PSM model selects the individuals that are similar in all respects with those in the treatment group except the eligibility for health insurance, which allows the treatment group and control group to be more comparable. Based on the estimated scores with probit regression, we used the nearest neighbour matching method to estimate the average effect of health insurance on child health, which was reported in column 1 of Table 4. Like the finding in column 2 of Table 3, we found that the HAZ score of matched-insured children was significantly higher than that of their non-insured counterparts, signifying that health insurance can significantly raise the health status of Chinese children. This probability is estimated of 0.143 at a significant level of $1 \%$, slightly higher than the estimate using the IV probit model.

In the CHNS, children aged over 10 were required to fill the survey questions by themselves while the children under the age of 10 were assisted by their parents to answer the questions. Though reporting by parent proxy increases the response rate to the survey, results might be biased. A few studies have indicated the reliability and validity of child reports by parent proxy (Rice et al. 2013; Varni et al. 2007). Other studies, however, have shown that there may exist significant disparities between selfand proxy-reports (Sakshaug 2014; Shields 2000). Therefore, we examined whether we would obtain similar results as the main analysis by focusing on a sample of children above 10 years without assistance from a proxy parent. Column 2 of Table 4 presented the estimated marginal results for this sub-sample. As indicated, children over 10 with access to medical insurance have a lower probability of being stunted by $10.2 \%$ than their non-insured counterparts, which is statistically significant at a level of $1 \%$.

Third, we used the BMI index to measure the impact of medical insurance on child health. BMI is viewed as a comprehensive health indicator and can be used to measure the dynamic changes of people's health. $B M I Z_{i j}$ refers to the BMIZ index for a child $i$ in the group $j$ defined by children's gender and age. The method to define $B M I Z_{\text {scoreij }}$ is similar to $H A Z_{\text {scoreij. }} B M I Z_{\text {scoreij }}$ is equal to zero if $B M I Z_{i j}$ is either two standard deviations or more above or below the BMI mean of the reference child group defined by the WHO; $B M I Z_{\text {scoreij }}$ is equal to one if $B M I Z_{i j}$ is within two standard deviations from the BMI mean of the reference group.

The estimated results are reported in column 3 of Table 4. Consistent with our expectation, enrolling in public medical insurance is associated with an $8.4 \%$ higher probability of children having a satisfactory BMIZ score, with a statistically significant level at $5 \%$.

\section{Path analysis}

To disentangle the health insurance effect between insurance enrollment and health status, we attempted to reveal the paths through which public medical insurance improved child health. We examined three plausible paths regarding health 
Table 4 Robustness Analysis

\begin{tabular}{|c|c|c|c|}
\hline \multirow[t]{2}{*}{ Dep. Var. = } & $\begin{array}{l}\text { HAZ }_{\text {score }} \\
\text { Alternative model (PSM) }\end{array}$ & $\begin{array}{l}\mathrm{HAZ}_{\text {score }} \\
\text { Alternative sample } \\
\text { (child aged above 10) }\end{array}$ & $\begin{array}{l}\mathrm{BMIZ}_{\text {score }} \\
\text { Alternative health (BMI) }\end{array}$ \\
\hline & (1) & (2) & (3) \\
\hline$\widehat{\text { Insurance }}$ & $\begin{array}{l}0.143 * * * \\
(0.036)\end{array}$ & $\begin{array}{l}0.102 * * \\
(0.052)\end{array}$ & $\begin{array}{l}0.084 * * \\
(0.037)\end{array}$ \\
\hline Male & $\begin{array}{l}-0.002 \\
(0.008)\end{array}$ & $\begin{array}{l}-0.022^{*} \\
(0.012)\end{array}$ & $\begin{array}{l}-0.017 * \\
(0.009)\end{array}$ \\
\hline Age & $\begin{array}{l}-0.001 * * * \\
(0.000)\end{array}$ & $\begin{array}{ll}- \\
- \\
-\end{array}$ & $\begin{array}{l}0.005^{* * * *} \\
(0.000)\end{array}$ \\
\hline Weight & $\begin{array}{ll}- \\
- \\
-\end{array}$ & $\begin{array}{l}0.015^{* *} \\
(0.001)\end{array}$ & $\begin{array}{l}-0.014 * * * \\
(0.001)\end{array}$ \\
\hline Sleep time & $\begin{array}{l}-0.008^{* *} \\
(0.004)\end{array}$ & $\begin{array}{l}0.005 \\
(0.006)\end{array}$ & $\begin{array}{l}-0.006 * \\
(0.003)\end{array}$ \\
\hline Rural & $\begin{array}{l}-0.057 * * * \\
(0.013)\end{array}$ & $\begin{array}{l}-0.050 * * * \\
(0.018)\end{array}$ & $\begin{array}{l}0.003 \\
(0.014)\end{array}$ \\
\hline Ln(income) & $\begin{array}{l}0.005 \\
(0.004)\end{array}$ & $\begin{array}{l}0.006 \\
(0.006)\end{array}$ & $\begin{array}{l}-0.010 * * * \\
(0.005)\end{array}$ \\
\hline Height_p & $\begin{array}{l}0.004 * * * \\
(0.001)\end{array}$ & $\begin{array}{l}0.004 * * \\
(0.002)\end{array}$ & $\begin{array}{l}0.002 \\
(0.001)\end{array}$ \\
\hline Weight_p & $\begin{array}{l}0.003 * * * \\
(0.001)\end{array}$ & $\begin{array}{l}-0.002 * \\
(0.001)\end{array}$ & $\begin{array}{l}-0.004^{* * * *} \\
(0.001)\end{array}$ \\
\hline Age_p & $\begin{array}{l}0.000 \\
(0.001)\end{array}$ & $\begin{array}{l}-0.007 * * * \\
(0.001)\end{array}$ & $\begin{array}{l}-0.000 \\
(0.001)\end{array}$ \\
\hline Parental education & & & \\
\hline Middle school & $\begin{array}{l}0.023^{* *} \\
(0.010)\end{array}$ & $\begin{array}{l}0.016 \\
(0.015)\end{array}$ & $\begin{array}{l}0.015 \\
(0.011)\end{array}$ \\
\hline High school & $\begin{array}{l}0.016 \\
(0.013)\end{array}$ & $\begin{array}{l}0.009 \\
(0.020)\end{array}$ & $\begin{array}{l}0.023 \\
(0.015)\end{array}$ \\
\hline College or more & $\begin{array}{l}0.028 * * \\
(0.014)\end{array}$ & $\begin{array}{l}0.012 \\
(0.025)\end{array}$ & $\begin{array}{l}0.063 * * * \\
(0.013)\end{array}$ \\
\hline Flush toilet & $\begin{array}{l}0.017 \\
(0.010)\end{array}$ & $\begin{array}{l}0.000 \\
(0.014)\end{array}$ & $\begin{array}{l}0.023 * * \\
(0.011)\end{array}$ \\
\hline Tap water & $\begin{array}{l}-0.007 \\
(0.010)\end{array}$ & $\begin{array}{l}-0.006 \\
(0.015)\end{array}$ & $\begin{array}{l}-0.029 * * * \\
(0.011)\end{array}$ \\
\hline Observations & 5139 & 2525 & 5786 \\
\hline Log-likelihood & -3485 & -1571 & -4316 \\
\hline$F$-statistics & $268.99 * * *(\mathrm{p}=0.000)$ & $170.69 * * *(\mathrm{p}=0.000)$ & $301.109 * * *(\mathrm{p}=0.000)$ \\
\hline Wald test & $12.91 * * *(\mathrm{p}=0.000)$ & $2.45(\mathrm{p}=0.1176)$ & $4.11^{* *}(\mathrm{p}=0.0428)$ \\
\hline
\end{tabular}

Standard errors are in parentheses. The model also controlled for the time fixed effects by including the dummy variable of 'year'. Due to space limitations, this effect was not included in this table $* * * \mathrm{p}<0.01, * * \mathrm{p}<0.05, * \mathrm{p}<0.1$ 
behaviour, service utilization and nutritional intake to explore how medical insurance affected child health. According to Wehby (2014), parents who have obtained health insurance coverage for their children are more likely to provide a healthy household environment. Hence, the first path refers to health-related behaviour, including the variables of whether a child is actively engaged in sports, whether a child's parents participate in any sports, and whether the child's parents have a craving for tobacco, taking a value of one if at least one parent smoked more than ten cigarettes per day. Children and their parents are considered participating in sports if they played any sports in the past week, such as volleyball, badminton or football. Since the introduction and expansion of children's eligibility for health insurance is more likely to increase child visits to physicians and uses of preventive care services (Currie et al. 2008; Currie and Gruber 1996a; Dafny and Gruber 2005; Wehby 2013), the second path refers to health service utilization, including the variables of whether a child visited any formal medical institutions for treatments in the past 4 weeks, and whether a child received any kind of health care services (such as regular health examinations, eye examinations and blood tests) in the past 4 weeks. There also exists evidence that health insurance can ease financial stress and increase nonmedical consumption (Miller et al. 2009; Bai and Wu 2014). Based on that, the third path refers to nutritional intake. We used an average three-day fat intake (Lnfat) of each household to explore the possible dietary effects on child health. These path variables are listed in Table 1 and the descriptive statistics are described in Table 2.

Using the HAZ score as a health indicator, we conducted the path analysis in two steps. The results in both steps are estimated using the IV probit model. First, we used the variable, insurance, to regress the possible path variables after controlling for the demographic characteristics of children, parents and families. If an estimated coefficient on a possible path variable was significant, then it was highly likely to be an effective path that determines the insurance effect on health. In the second step, we gradually added the three groups of likely path variables into the IV probit model, presented in Eqs. 3 and 4. If the health status of children was indeed affected through path variables, the estimated coefficient of medical insurance in Eq. 4 would be lowered or become less significant when the health-behaviour, service-utilization and nutrition-intake related variables were controlled.

Table 5 presents the estimated results of path identification, the first step of path analysis. As indicated in column 2, medical insurance has no significant impact on parental decisions of whether regularly participating in any sports. Except for that, medical insurance has demonstrated significant effects on all the other path variables in other columns. According to this, we gradually added these likely path variables into the Eq. 4, where $\mathrm{HAZ}_{\text {score }}$ is adopted to measure child health. Table 6 reports the estimated results of path effects, calculated in the second step of path analysis. As indicated in column 1, after adding the path variable of whether children participate in exercises in the baseline model, the estimated marginal effect of medical insurance on child health is reduced by $3.5 \%$, from an initial value of $0.113-0.109$. However, we did not find any significant changes in the estimated insurance marginal effect in Column 2, 3 and 4 when adding parental smoking decision and service-utilization related path variables. After adding the variable of fat intake in column 5 of Table 6, the estimated marginal effect of medical insurance on child health 


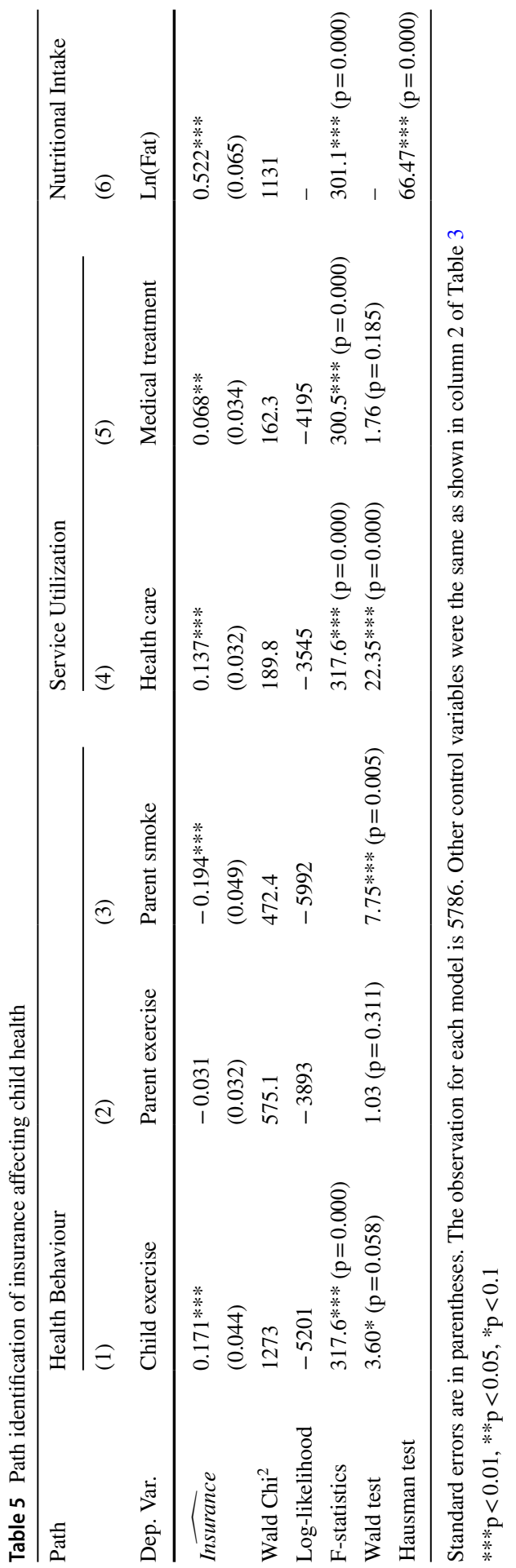




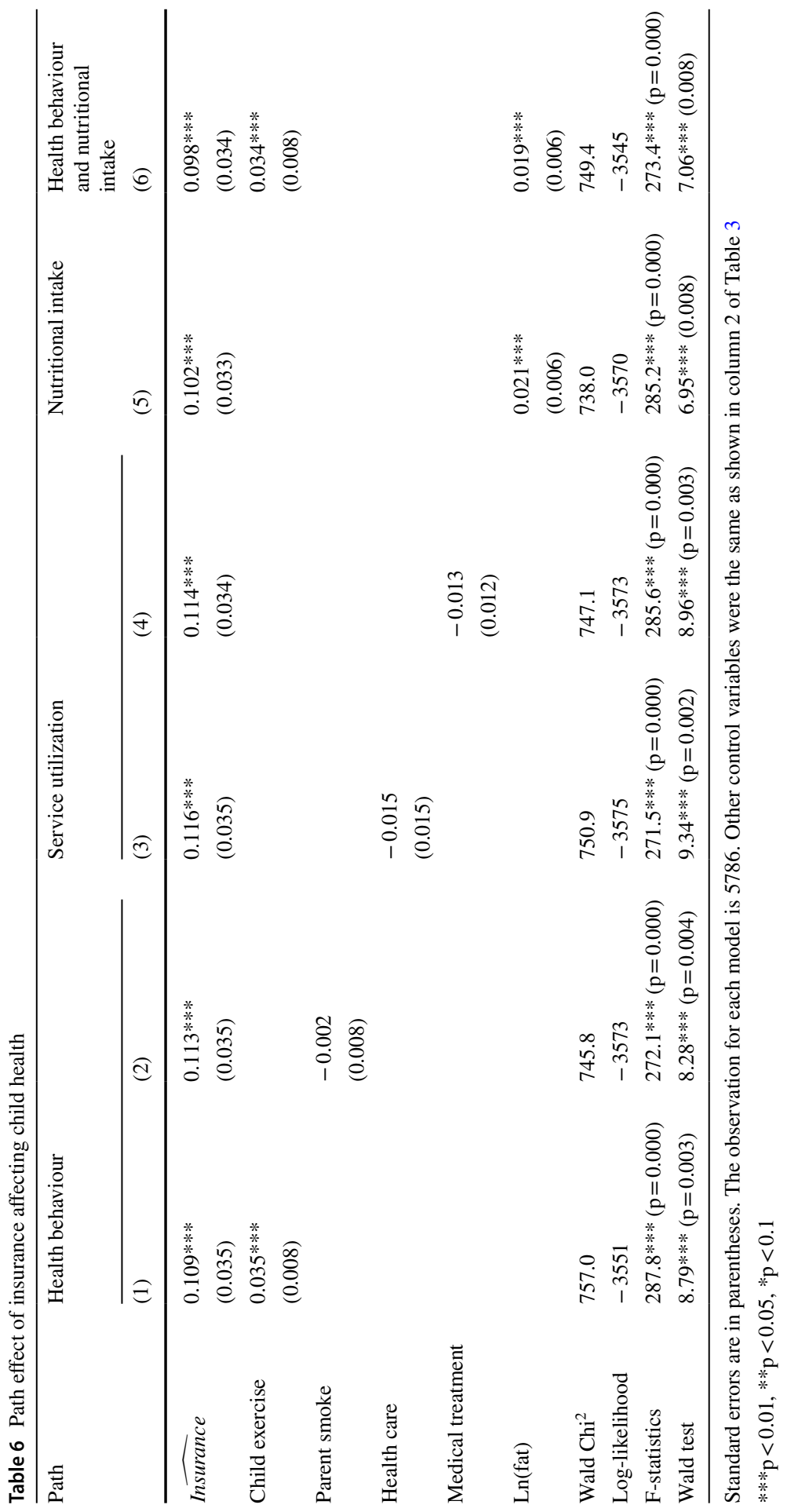


is lowered from 0.113 to 0.102 , suggesting that fat intake is a valid path between insurance enrollment and child health. After adding all the promising path variables in column 6, the marginal health effect on Chinese children was further dropped from 0.102 to 0.098 .

To sum up, Tables 5 and 6 indicates that child health behaviour and nutritional intake are the effective paths through which public medical insurance benefits children's health in China. These two paths can explain $13.2 \%\left(=\frac{0.113-0.098}{0.113} \times 100 \%\right)$ of the total insurance effect on child health.

\section{Discussion}

Consistent with prior research (Currie 1995; Joyce and Racine 2005), our empirical results show that the coverage of medical insurance has positive impacts on children's health, which affirms the effectiveness of the efforts and allocation of economic resources made by the government to promote children's health. However, the heterogeneity exists in health insurance effects across hukou. The effect of public insurance is significantly larger on urban children than rural children in China. The coverages of the NRCMS and URBMI, such as annual insurance premium, percentage of outpatient and inpatient fees covered by insurance, deductibles, spending cap, may be quite different from each other. These differences perhaps explain why they have such different effects on children's health status in rural and urban areas. Furthermore, we found the current coverage of public medical insurance did not significantly improve the utilization of health service, which was primarily due to partial inpatient cost covered by the NRCMS and URBMI.

These findings provide implications and insights on how the government can improve relevant health insurance policies, effectively target separate groups and promote children's health. First, since basic medical insurance for urban and rural residents was promoted in 2016, the coverage and capability levels should be further adjusted and extended, so as to improve medical accessibility of insured children's families. As a result, the utilization of medical services can be promoted, and eventually improve the health of children through the path effect of service utilization. Second, the Chinese government should promote active health management to improve children's health through shaping parents' and children's active lifestyles and healthy eating habits. Lastly, in rural areas, the government should expand the allocation of medical institutions and personnel to address the shortage of health care facilities and achieve medical access in rural China.

\section{Conclusion}

In this paper, we found the access to public health insurance led to better health of children in China. Our results revealed that the heterogeneity in the effect of medical insurance on child health exists. The health insurance effect is significantly stronger for urban children than rural children. We further disentangled the paths through which child health was promoted by medical insurance. We found that the positive 
impact of medical insurance on child health in China was primarily resulting from the health-behaviour and nutrition-intake related channels, either through more child physical exercise, or more nutritional intake, to achieve effective disease prevention and health management. These findings can provide implications for policy makers to construct and develop the medical insurance system for children in China.

There exist three major limitations in this study. First, though the CHNS is a longitudinal data set, the data in the waves of 2004, 2006, 2009 and 2011 is a significantly unbalanced dataset. Hence, we could not control for the time-invariant individual heterogeneity using the fixed-effect model. Second, due to data limitation, we were unable to examine how the capability and content of health insurance could affect children's health. Third, besides the paths through which medical insurance promotes children's health, individual insurance enrollment might be a path between household income and child health. However, this topic is beyond the scope of this study. All these issues might be explored in further research when relevant information and resources are available.

Acknowledgements This research was funded by the National Social Science Foundation of China (No. 16BRK019).

\section{References}

Allen, H., Baicker, K., Finkelstein, A., Taubman, S., Wright, B. J., \& The Oregon Health Study Group. (2010). What the Oregon health study can tell us about expanding Medicaid. Health Affairs, 29(8), 1498-1506.

Ampaabeng, S. K., \& Tan, C. M. (2013). The long-term cognitive consequences of early childhood malnutrition: The case of famine in Ghana. Journal of Health Economics, 32(6), 1013-1027.

Bai, C., \& Wu, B. (2014). Health insurance and consumption: Evidence from China's new cooperative medical scheme. Journal of Comparative Economics, 42(2), 450-469.

Brook, R. H., Ware, J. E., Rogers, W. H., Keeler, E. B., Davies, A. R., \& Donald, C. A. (1983). Does free care improve adults' health? Results from a randomized controlled trial. The New England Journal of Medicine, 309(23), 1426-1434.

Brown, M. E., Bindman, A. B., \& Lurie, N. (1998). Monitoring the consequences of uninsurance: A review of methodologies. Medical Care Research and Review, 55(2), 177-210.

Chen, Z., Eastwood, D. B., \& Yen, S. T. (2007). A decade's story of childhood malnutrition inequality in China: Where you live does matter. China Economic Review, 18(2), 139-154.

Chen, Y., \& Jin, Z. G. (2012). Does health insurance coverage lead to better health and educational outcomes? Evidence from rural China. Journal of Health Economics, 31(1), 1-14.

Chen, L., Wu, Y., \& Coyte, C. P. (2014). Income-related children's health inequality and health achievement in China. International Journal for Equity in Health, 10(1), 1-12.

Courtemanche, C., Marton, J., Ukert, B., Yelowitz, A., \& Zapata, D. (2017). Early effects of the Affordable Care Act on health care access, risky health behaviors, and self-assessed health (No. 23269). NBER Working Paper Series.

Currie, J. (1995). Socio-economic status and child health: Does public health insurance narrow the gap? The Scandinavian Journal of Economics, 97(4), 603-620.

Currie, J., Decker, S., \& Lin, W. (2008). Has public health insurance for older children reduced disparities in access to care and health outcomes? Journal of Health Economics, 27(6), 1567-1581.

Currie, J., \& Gruber, J. (1996a). Health insurance eligibility, utilization of medical care, and child health. Quarterly Journal of Economics, 111, 431-466.

Currie, J., \& Gruber, J. (1996b). Babies: The efficacy and cost of recent changes in the Medicaid eligibility of pregnant women. Journal of Political Economy, 104(6), 1263-1296. 
Dafny, L., \& Gruber, J. (2005). Public insurance and child hospitalizations: Access and efficiency effects. Journal of Public Economics, 89(1), 109-129.

De La Mata, D. (2012). The effect of Medicaid eligibility on coverage, utilization and children's health. Health Economics, 21(9), 1061-1079.

Dehejia, R., \& Wahba, S. (2002). Propensity score-matching methods for nonexperimental causal studies. Review of Economics and Statistics, 84(1), 151-161.

Dor, A., Sudano, J., \& Baker, D. W. (2006). The effect of private insurance on the labor of older, working age adults: Evidence from the Health and Retirement Study. Health Services Research, 41(3), 759-787.

Goode, A., Mavromaras, K., \& Zhu, R. (2014). Family income and child health in China. China Economic Review, 29, 152-165.

Grossman, M. (1972). On the concept of health capital and the demand for health. The Journal of Political Economy, 80(2), 223-255.

Hadley, J. (2003). Sicker and poorer: the consequences of being uninsured: A review of the research on the relationship between health insurance, medical care use, health, work, and income. Medical Care Research and Review, 60(2 Suppl), 3S-75S.

Howell, E., Decker, S., Hogan, S., Yemane, A., \& Foster, J. (2010). Declining child mortality and continuing racial disparities in the era of the Medicaid and SCHIP insurance coverage expansions. American Journal of Public Health, 100(12), 2500-2506.

Howell, E., \& Kenney, G. (2012). The impact of the Medicaid/CHIP expansions on children: A synthesis of the evidence. Medical Care Research and Review, 69(4), 372-396.

Joyce, T., \& Racine, A. (2005). Chip shots: Association between the state children's health insurance programs and immunization coverage and delivery. Pediatrics, 115(5), e526-e534.

Lei, X., \& Lin, W. (2009). The new cooperative medical scheme in rural China: Does more coverage mean more service and better health? Health Economics, 18(Suppl 2), S25-S46.

Leininger, L., \& Levy, H. (2015). Child health and access to medical care. Future of Children, 25(1), 65-90.

Levy, H., \& Meltzer, D. (2001). What do we really know about whether health insurance affects health? University of Chicago Harris School of Public Policy. Working Paper.

Levy, H., \& Meltzer, D. (2008). The impact of health insurance on health. The Annual Review of Public Health, 29, 399-409.

Liu, H., Fang, H., \& Zhao, Z. (2013). Urban-rural disparities of child health and nutritional status in China from 1989 to 2006. Economics and Human Biology, 11(3), 294-309.

Liu, H., \& Zhao, Z. (2014). Does health insurance matter? Evidence from China's urban resident basic medical insurance. Journal of Comparative Economics, 42(4), 1007-1020.

Lucas, R. J. (1988). On the mechanics or economic development. Journal of Monetary Economics, 22(1), $3-42$.

Miller, G., Pinto, D. M., \&Vera-Hernandez, M. (2009). High-powered incentives in developing country health insurance: evidence from Colombia's Regimen Subsidiado (No. 15456). NBER Working Paper Series.

Miller, S., \& Wherry, L. R. (2017). Health and access to care during the first 2 years of the ACA medicaid expansions. The New England Journal of Medicine, 376(10), 947-956.

Naudeau, S., Kataoka, N., Valerio, A., Neuman, M., \& Elder, L. L. (2011). Investing in young children: An early childhood development guide for policy dialogue and project preparation. Washington, DC: World Bank.

Newhouse, J. P., \& The Insurance Experiment Group. (1993). Free for all? Lessons from the RAND health insurance experiment. Cambridge, MA: Harvard University Press.

Osberg, L., Shao, J., \& Xu, K. (2009). The growth of poor children in China 1991-2000: Why food subsidies may matter. Health Economics, 18(S1), 89-108.

Peng, X., \& Conley, D. (2016). The implication of health insurance for child development and maternal nutrition: Evidence from China. The European Journal of Health Economics, 17, 521-534.

Perry, C. W., \& Rosen, H. S. (2001). The Self-employed are less likely to have health insurance than wage earners. So what? (No. 8316). NBER Working Paper Series.

Pincus, T., Esther, R., DeWalt, D. A., \& Callahan, L. F. (1998). Social conditions and self-management are more powerful determinants of health than access to care. Annals of Internal Medicine, 129(5), 406-411.

Rice, K. R., Joschtel, B., \& Trost, S. G. (2013). Validity of family child care providers' proxy reports on children's physical activity. Childhood obesity, 9(5), 393-398. 
Roseboom, T., de Rooij, S., \& Painter, R. (2006). The Dutch famine and its long-term consequences for adult health. Early Human Development, 82(8), 485-491.

Rosenbaum, P. R., \& Rubin, D. B. (1983). The central role of the propensity score in observational studies for causal effects. Biometrika, 70(1), 41-55.

Ross, C. E., \& Mirowsky, J. (2000). Does medical insurance contribute to socioeconomic differentials in health? Milbank Quarterly, 78(2), 151-152.

Sakshaug, J. W. (2014). Proxy reporting in health surveys. In T. P. Johnson (Ed.), Health survey methods (pp. 367-381). New Jersey: Wiley.

Shields, M. (2000). Proxy reporting in the national population health survey. Health Reports, 12(1), 21-39.

Sommers, B. D., Baicker, K., \& Epstein, A. M. (2012). Mortality and access to care among adults after state Medicaid expansions. The New England Journal of Medicines, 367(11), 1025-1034.

Sommers, B. D., Gawande, A. A., \& Baicker, K. (2017). Health insurance coverage and health what the recent evidence tells us. The New England Journal of Medicine, 377, 586-593.

Varni, J. W., Limbers, C. A., \& Burwinke, T. M. (2007). Parent proxy-report of their children's healthrelated quality of life: an analysis of 13,878 parents' reliability and validity across age subgroups using the PedsQL 4.0 generic core scales. Health and Quality of Life Outcomes, 5(1), 2.

Wagstaff, A., van Doorslaer, E., \& Watanabe, N. (2003). On decomposing the causes of health sector inequalities with an application to malnutrition inequalities in Vietnam. Journal of Econometrics, 112(1), 207-223.

Wehby, G. L. (2013). Child health insurance and early preventive care in three South American countries. Health Policy Plan, 28(3), 328-338.

Wehby, G. L. (2014). Child health insurance coverage and household activity toward child development in four south American Countries. Maternal and Child Health Journal, 18(4), 939-949.

Zhou, Q., Jiang, W., \& Guo, X. (2018). The effect of social insurance on mental health among rural residents: an empirical analysis based on CHARLS data. China Economic Studies, 5(3), 125-136.

Zhou, Q., Yuan, Y., \& Zang, W. (2015). The study of health insurance on households' portfolio choice in urban and rural China. China Economic Quarterly, 14(3), 931-960.

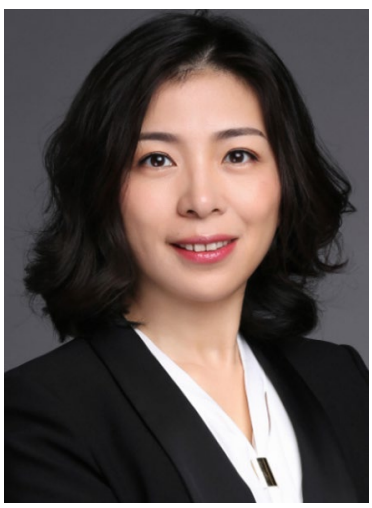

Lu Chen is a professor at the Department of Risk Management and Insurance, School of Finance, Nankai University of China. She is the Director of Research Center of Health Aging and Social Security of Nankai University of China. Her main research interests are health economics, population aging. 


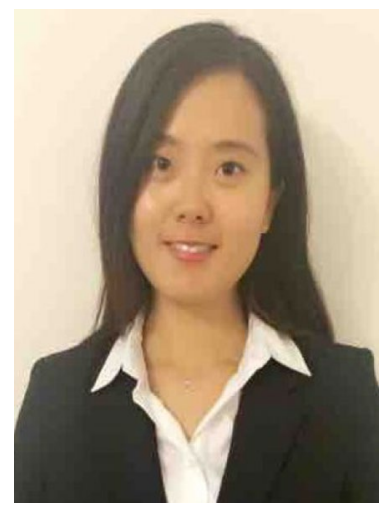

Lanlan Chu is an assistant professor of economics in Harold Walter Siebens School of Business, Buena Vista University. Her current research interests are industrial organization, health economics, aging, and caregiving. 